\title{
Reconceptualizing Climate Change Denial: Ideological Denialism Misdiagnoses Climate Change and Limits Effective Action
}

\author{
Brian Petersen' \\ Planning and Recreation, Department of Geography \\ Northern Arizona University, United States \\ Diana Stuart \\ Sustainable Communities Program, School of Earth Sciences \\ and Environmental Sustainability \\ Northern Arizona University, United States \\ Ryan Gunderson \\ Department of Sociology and Gerontology \\ Miami University, Florida, United States
}

\section{Abstract}

Despite increasing scientific evidence supporting the need for immediate and transformative action, effective responses to address climate change remain stymied. Scholars have identified climate change denial as a factor in thwarting policy responses to climate change. We examine new forms of climate change denial that are critical to recognize as the general public and policy-makers consider actions to limit warming. Here we apply a Marxist conception of ideology to broaden our understanding of climate denialism (Marx \& Engels, 1977). We introduce the concept of "ideological denialism," which conceals underlying contradictions and perpetuates the current social order. The ideological denial of climate change involves recognizing climate change as a problem, yet fails to diagnose the root causes and prescribes solutions that maintain the current system. We argue that ideological denialism typically stems from a failure to recognize a growth-dependent economic system as a root driver of climate change. We examine degrowth as a possible means to reorganize social relations with potential to more effectively reduce greenhouse gas emissions and limit global warming.

Key words: climate change, contradictions, degrowth, denialism, ideology

1 Corresponding author: brian.petersen@nau.edu 
It is vital, when encountering a serious problem, not merely to try to solve the problem in itself but to confront and transform the processes that gave rise to the problem in the first place.

David Harvey (1973, pp. 136-137)

\section{Introduction}

The Intergovernmental Panel on Climate Change (IPCC) special report released in October 2018 describes the significant impacts from global temperature increases and states that "rapid, far-reaching and unprecedented changes in all aspects of society" are necessary to keep Earth's temperature within 1.5 degrees Celsius above pre-industrial levels (IPCC, 2018). Despite overwhelming evidence and increasingly dire predictions, including the possibility of "Hothouse Earth" (Steffen et al., 2018), current policies and international agreements will fail to prevent warming to temperatures that will have severe impacts on ecosystems, society, and the economy (IPCC, 2018). Climate denialism has been identified as a prominent reason as to why effective policies to reduce greenhouse gas emissions have not gained enough support, especially in the United States, with scholars primarily focusing on moneyed and special interests intentionally misleading the public (McCright $\&$ Dunlap, 2000, 2003, 2010, 2011).

Here, we aim to broaden the concept of climate change denialism. In addition to actors protecting their financial interests, who have undoubtedly undermined efforts to address climate change, we argue that new forms of denial apply even to those who agree that climate change is occurring. These new forms of denial are based on what we call an "ideological" form of denialism that fails to identify the root causes of climate change and therefore promotes insufficient solutions that maintain the current social order, a social order whose basic structure drives climate change. As stated in the IPCC special report (2018), the scope and scale of climate change demands radical societal change. Radical, from the Latin radicalis, means relating to the root. In this context, climate action necessitates identifying and overcoming the root causes of greenhouse gas emissions. As we will illustrate with evidence later, a growth-dependent economic system is a central root driver.

Rather than focusing solely on obvious climate denialists - those who claim no scientific evidence exists that humans are changing the climate-a need has emerged to better understand the forms of denial that continue to prevent those who do believe in anthropocentric climate change from taking effective action. In addition to persuading those reluctant to address climate change, we also need to "preach to the choir," coaxing the already persuaded to understand that, due in part to ideology, they have both misdiagnosed the problem and are relying on limited solutions that will not only fail to effectively achieve deep emissions cuts but may 
even distract attention from effective and just mitigation strategies. As we will illustrate, prominent proposed and implemented solutions are not radical in the sense that they fail to address the root drivers of climate change. Climate change "solutions" that do not address root drivers of emissions effectively deny the reality of the problem and the social transformations necessary to address it. In Section 2, drawing from Foster (2010) and others, we develop the notion of "ideological denialism" to conceptualize the paradox of climate change solutions that effectively deny the reality of climate change.

In this paper, we first conceptualize “ideological denialism." We next identify six different forms of climate change denial: literal denial, neo-skepticism, technooptimism (including three variants), individualism, market fundamentalism, and green growthism. After reviewing the forms of denialism, we propose and explore "degrowth" as a viable and necessary response, an approach that begins to heed Foster's (2010) call for a strategy that calls into question the social formation that drives climate change. We conclude, briefly, by summarizing ideological denialism and detailing its implications related to climate change.

\section{Ideological denialism}

We use the term ideology as Marx did, as "ideas and practices that reproduce contradictory social relations" (Gunderson, 2017, p. 271). Ideology obscures or masks social contradictions, fashions social unity in spite of division, narrows political horizons, and limits actions toward social change. As opposed to remaining only a taken-for-granted practice or an immaterial, intellectual "ism," ideology also exists as unreflected activities governed by rituals within specific institutions or "ideological state apparatuses" (Althusser 1971). The content of ideology in the form of ideas reproduces the status quo through reification and legitimation. Reification refers to the process by which humans are dominated by their own material and immaterial artifacts (the objective dimension of reification), yet these artifacts appear as fixed and unchangeable rather than as human creations that can be changed (the subjective dimension of reification that concerns us here) (Lukács, 1971). One aspect of subjective reification important for this project is blinding consciousness to possible alternative social futures (Lukács, 1971, p. 192). This blindness to possibility was famously described by Marcuse (1964) as "onedimensional" thinking (see Conclusion). The implication of possibility blindness is this: "reification effectively prevents questioning and changing established social relations in modern societies" (Kavoulakos, 2017, p. 69).

Along with reification, ideology masks social contradictions and reproduces the status quo through legitimation via consent. Gramsci's (1971) conception of "hegemonic ideology" shows how culture and civil institutions generate social acceptance of 
ideas (ideology) that ultimately prevent social change. The concept of hegemony is often employed to make a distinction between power through domination won through coercive institutions (the police, military, state bureaucracy), on the one hand, and power through consensus (hegemony) won through civil institutions (e.g., church, family, unions), on the other (Ramos, 1982). A Gramscian conception of ideology also showcases "how the ideas of elite political and economic actors come to be seen as common sense to the general public, and how control in modern societies is maintained though consent to 'ruling ideas' rather than through direct imposition of force" (Norgaard, 2011, p. 11). We argue that these "ruling ideas" give life to different forms of climate denialism, dramatically limiting the suite of options seen as solutions to climate change. Further, the concept of ideology adopted here, as contradiction-concealing ideas and practices that reproduce existing social conditions, lends itself to comparison with the notion of denial.

Denialism has received significant attention due to how it influences society's responses to climate change. In her study of climate change perspectives from educated, economically stable people in Norway, Norgaard (2011) outlines how denial emerges through social interaction. Rather than focusing on the psychological realities that limit humans from viewing climate change as an immediate risk that requires action, Norgaard (2011, p. 9) suggests that "the notion of socially organized denial emphasizes that ignoring occurs in response to social circumstances and is carried out through a process of social interactions." Norgaard (2011) draws from Cohen (2001) in formulating denialism. Cohen crafted a three-part denial typology: literal, interpretive, and implicatory. Literal denial refers to someone asserting something is not true despite evidence to the contrary. Interpretive denial focuses on contesting or distorting facts and evidence in an attempt to change the meaning associated with ideas or events. Lastly, implicatory denial, the variant that Norgaard focuses on, conceals information such that individuals and, more importantly, society, do not act upon it. She develops the idea of socially organized denial, in which individuals distance themselves from information based on "norms of emotion, conversation, and attention" (Norgaard, 2011, p. 211). This leads to individual apathy and a situation where people "find real change unnecessary" (Norgaard, 2011, p. 225).

Foster (2010) also draws on the concept of denial to diagnose why society has failed to adequately address climate change. He too focuses attention on dominant views held by those convinced that climate change is happening. He contributes to this line of thought by identifying as denial prominent strategies put forth by environmentalists, a use of the concept that we extend in this article. Mainstream strategies are labeled a form of denial because the strategies remain woefully inadequate to addressing the systemic factors causing climate change. Recently, Foster (as quoted in Ferguson, 2018, n.p.) stated that "the willful delusions here are in some ways more dangerous than that of straight-out climate deniers, since they 
are subtler and infect those who are ostensibly on the side of change." He marshals evidence that climate change poses significant threats to society, notes that the current trends represent an unsustainable pathway, and suggests the only ways to address the situation require radical alternatives. In particular, Foster raises tipping points as specific climate change consequences that pose grave threats to society. Still, environmental discourses refrain from engaging the gravity, scope, and extent of the drivers causing climate change. Foster (2010) explains:

However, rather than addressing the real roots of the crisis and drawing the appropriate conclusions, the dominant response is to avoid all questions about the nature of our society, and to turn to technological fixes or market mechanisms of one sort or another. In this respect, there is a certain continuity of thought between those who deny the climate change problem altogether, and those who, while acknowledging the severity of the problem at one level, nevertheless deny that it requires a revolution in our social system. (p. 4)

Foster (2010) points to what we mean by the ideological denial of climate change, a mode of denialism that:

- acknowledges the reality, human origins, and severity of climate change and desires immediate action;

- often misdiagnoses the structural drivers of climate change;

- limits more effective actions; and

- reproduces rather than challenges the social formation that drives climate change.

In comparison to Norgaard's (2011) notion of the socially organized implicatory denial of climate change, which illuminates how climate change knowledge is severed from action, the notion of ideological denialism illuminates ineffective action despite climate change knowledge. As argued in the following section, there are four dominant forms of ideological denialism in mainstream climate policy today: techno-optimism, individualism, market fundamentalism, and green growthism.

\section{Forms of climate change denial}

In this section we detail six forms of denial associated with climate change. These forms include what is typically referred to as climate change denial, denying the existence of climate change or its human origins, as well as climate "neo-skepticism," denying the severity of possible consequences to society. We then go beyond these frequently identified forms of denial and categorize additional ideologicaldenialist forms that involve relying on solutions to climate change that focus on individual, technological, or market approaches and fail to address the root drivers increasing emissions. Although some of these approaches hold potential for positive change, they have been construed narrowly and fail to "engage the nature of 
society," as Foster (2010) calls for. Each overview below represents only a cursory introduction. We offer discrete descriptions to clearly articulate each form but do not contend they are mutually exclusive.

\subsection{Literal denial}

The overwhelming scientific evidence that climate change is occurring has not translated into social consensus. Theories abound as to what has created this discrepancy. Some attribute it to evolution and brain wiring (see Walsh, 2019), while others attribute it to climate change not animating a moral response, or to psychological barriers (e.g., Mooney, 2011). Undoubtedly, many factors have contributed to literal climate denialism. However, substantial evidence suggests that a well-organized denial campaign has had a significant influence (McCright $\&$ Dunlap, 2000).

Climate change has important implications for society. As a result, certain groups initiated efforts dating back decades to intentionally forestall action to address climate change. The conservative movement in the United States began a campaign in the early 1990s to sow seeds of doubt about climate change in the American populace (McCright \& Dunlap, 2000). This effort, supported by the fossil fuel industry, successfully altered climate policy in the United States by helping to thwart ratification of the Kyoto Protocol (McCright \& Dunlap, 2003). Fossil fuel interests, especially ExxonMobil (Supran \& Oreskes, 2017), have funded think tanks and nongovernmental organizations as front groups to create controversy around climate change. Oreskes and Conway (2010) show how non-climate scientists and industry representatives attacked the IPCC and climate change reports to invalidate the notion that humans are causing climate change. These efforts to create climate denialism have led to confusion on the part of the public and political paralysis in taking action.

Diethelm and McKee (2009) outline five characteristics of denialism: identification of conspiracies, use of fake experts, selectivity in sources, creating impossible expectations of research and evidence, and using misrepresentation and logical fallacies. The conservative movement in particular has used these tactics effectively in a strategic effort to create confusion about climate science and negate policy interventions (McCright \& Dunlap, 2010). Overall, denialism has resulted in the public viewing science as uncertain or contradictory (Oreskes \& Conway, 2010) and deep divisions between individuals affiliated with different political parties (McCright \& Dunlap, 2011). This denial of the scientific evidence effectively influenced public opinion, stalling motivation to create policy responses (McCright \& Dunlap, 2010). 


\subsection{Neo-skepticism}

The term skepticism figures prominently in recent debates about climate change. Skepticism represents a foundation for scientific inquiry. It entails scientists critically analyzing claims to ensure they are scientifically credible and supported by evidence. Skepticism has taken on a different form in regard to climate discussions. A new variant, neo-skepticism, adds another dimension to this term. Coined by Perkins (2015, p. 287), neo-skeptics "do not deny anthropogenic global warming, but minimize its projected effects and see mitigation efforts as unjustifiable." He uses two Wall Street Journal articles to illustrate neo-skepticism, highlighting how scientists express uncertainty or minimize the extent of possible impacts. In the article "Climate Science Is Not Settled," Steven Koonin (2014), a computational physicist, acknowledged that humans have influenced climate, stating "that is no hoax: There is little doubt in the scientific community that continually growing amounts of greenhouse gases in the atmosphere, due largely to carbon-dioxide emissions from the conventional use of fossil fuels, are influencing the climate." He went on to contend, however, that science remains unable to predict what will happen in the future, based on uncertainties, thus calling into question the value or possibility of taking action.

Similarly, in "The Global Warming Statistical Meltdown," Curry (2014), a professor at the Georgia Institute of Technology, does not dispute climate change but challenges climate sensitivity to carbon emissions, arguing we have time to address climate change without implementing policies aimed at drastically reducing emissions.

Stern et al. (2016, p. 653) argue that in contrast to literal denialist arguments, neoskeptics marshal legitimate concerns and thus "raise important questions about ultimate impacts and response options." These concerns, however, often mask underlying interests and motivations. For example, Curry (2014) highlights work that she and her collaborators have done that indicates climate warming could be less than projected, a claim based on their statistical examination. She goes on to say, "this slower rate of warming — relative to climate model projections - means there is less urgency to phase out greenhouse gas emissions now, and more time to find ways to decarbonize the economy affordably" (emphasis added). This statement highlights her interest in the costs associated with addressing climate change and the emphasis on economics. Although Curry's analysis focused on the goal of remaining within 2 degrees Celsius above pre-industrial levels, more recent analyses suggest the world has only a 5\% chance of not exceeding a 2-degree increase by 2100 (Raftery et al., 2017), that the 2-degree threshold is arbitrary and represents more of a political than scientific threshold, that consequences have already materialized well below the 2-degree threshold, and that each additional 0.5 degree temperature increase portends significant consequences (Schleussner et al., 2017). Keeping global temperatures below the 2-degree threshold by century's end seems not only unlikely 
but increasingly implausible (Steffen et al., 2018). Despite this, neo-skeptics continue to argue that, while climate change is occurring, what we know about the impacts is either uncertain or not consequential enough to warrant immediate or significant action. Neo-skepticism therefore denies that climate change is a significant risk, or denies that the consequences are detrimental enough to avoid, and therefore denies the need for action.

\subsection{Techno-optimism}

Whereas the literal denial of climate change and neo-skepticism are commonly identified as forms of climate change denial, the rest of our analysis focuses on four expressions of the ideological denial of climate change: individualism, market fundamentalism, green growthism, and, in this section, techno-optimism. Solutions to environmental problems often take a Promethean or techno-optimistic form. As Dryzek et al. (2009, p. 266) explain, "Prometheans have faith in the capacity of humans to manipulate complex systems for their own advantage." Techno-optimists believe that technology can be used effectively to solve environmental problems. Mol's (2001) ecological modernization framework embodies this position. Mol (2001, p. 58) states, "environmental deterioration is conceived of as a challenge for socio-technical and economic reform, rather than the inevitable consequence of the current institutional structure."

Techno-optimism has received significant criticisms. For example, York and Clark (2010) discuss the social factors that influence environmental problems, and show how they cannot be addressed simply by technology. Foster (2010) argues that the focus on technology in climate policy is a form of denialism (see Section 2). Despite the critiques leveled, techno-optimism remains in fashion as an appropriate response to climate change. Here we focus on three variants of techno-optimism: calls for geoengineering, energy efficiency, and alternative energy.

\subsubsection{Techno-optimism: Geoengineering}

The IPCC defines geoengineering as "a broad set of methods and technologies that aim to deliberately alter the climate system in order to alleviate impacts of climate change" (Boucher et al., 2013). Geoengineering can take different forms: either removing carbon from the atmosphere (e.g., iron fertilization of oceans, bioenergy with carbon capture and storage) or reducing incoming solar radiation (e.g., mirrors in space, stratospheric aerosol injection). For example, stratospheric aerosol injection (SAI) is an approach that has gained widespread attention. Based on evidence that the Mount Pinatubo eruption in 1991 cooled Earth by 0.5 degrees Celsius (Robock et al., 2010), SAI would use various means to inject sulfur particles into the atmosphere to reflect incoming solar radiation and reduce global temperature 
increases (Keith, 2013). Proponents suggest the benefits of this approach outweigh the costs, it represents the only approach able to stave off global catastrophe, and it does so in a technologically feasible, relatively cheap, timely manner (Keith, 2013).

Techno-optimism in the form of geoengineering has significant shortcomings. SAI, for example, has unknown consequences for weather patterns, precipitation, and agricultural production (Robock, 2008); could potentially cause widespread drought; could lead to ozone depletion and increased ocean acidification; and poses grave risks due to human error or strategic militarization (Boucher et al., 2013; Robock, 2008). In addition, if SAI efforts, once initiated, do not continue, greenhouse gas levels that continued to increase would result in rapid warming and severe consequences.

Although perhaps technically feasible, geoengineering strategies do not address the root drivers of climate change. Narrowly construing the problem and potential solutions, geoengineering is the pinnacle of what Marcuse (1964) called technological rationality, which "molds all social and environmental problems into technological problems requiring technological solutions" (Gunderson, Petersen, \& Stuart, 2018, p. 6). SAI in particular proposes to literally mask the problem of climate change, leaving its causes intact (Gunderson et al., 2019), and, therefore, represents a denial that sociostructural change is necessary for mitigation.

\subsubsection{Techno-optimism: Energy efficiency}

Energy use plays a significant role in carbon emissions. As a result, a commonly proposed solution revolves around energy efficiency improvements. If we just used our energy resources more efficiently, the argument goes, we could reduce emissions. This assumed relationship has important policy implications. Although conceptually intuitive, the realities of energy use and efficiency do not represent a panacea. William Stanley Jevons interrogated the relationship between efficiency gains and resource use in the context of coal (York, 2006). He showed that efficiency in coal use decreased its costs and led to increased consumption, a relationship now known as Jevons' paradox. This paradox has been empirically illustrated as it relates to climate change. York and McGee (2016) found that countries with greater efficiencies have higher rates of carbon emissions, energy use, and electricity consumption. In addition, York (2006) shows how vehicle efficiency in the United States did not lead to reduced fuel consumption, in part due to changes in vehicle weights and types, drivers, and miles driven.

The counterintuitive outcome of the potential gains of energy efficiency being neutralized due to efficiency gains, and, in some cases increasing energy use, has been termed the rebound effect. For example, Freire-Gonzalez (2017) analyzed the rebound effect in households using energy efficiency improvements in the 27 countries of the European Union. The results from the analysis showed that seven countries 
had rebound effects above $100 \%$, in which more energy is consumed than prior to implementing improvements, and most countries showed at least a 50 percent rebound, meaning the rebound effect neutralized half the efficiency gains.

Sorrell (2009) differentiates between direct and indirect rebound effects. Direct rebound effects result from efficiency improvements reducing the marginal costs associated with service that then lead to increased consumption. Sorrell identifies five indirect rebound effects that include embodied energy effects (the energy used to create the energy improvements), respending effects (purchasing goods with savings from energy efficiency), output effects (output increases by producers with savings from efficiency), energy market effects (lower energy demand causes price drops, which leads to increases in energy consumption), and composition effects (reduction in the price of energy-intensive goods due to efficiency gains will decrease their price and lead to more consumption). This evidence suggests that, despite widespread support, energy efficiency alone will not be an effective solution to climate change, and may increase energy use, and its false promise helps to support the continuation of business as usual. Faith in energy efficiency, therefore, represents a form of techno-optimism supporting the denial of necessary social changes.

\subsubsection{Techno-optimism: Renewable energy}

Few solutions to climate change have received as much attention as switching to renewable energy. The United Nations Development Programme (n.d.) states: "The role of renewable energy solutions in mitigating climate change is proven." Renewable energy represents an attractive solution because it presents an opportunity to replace, or more importantly displace, fossil fuel-based energy with carbon-free sources. Doing so would enable society to meet energy demand without contributing to climate change. Despite its potential, however, renewable energy development has not materialized into an effective response to climate change.

The idea of renewable energy reducing greenhouse gas emissions relies on the assumption that renewable energy production will displace fossil fuels. Empirical analyses suggest displacement does not occur and that renewable energy production might counterintuitively increase overall energy use, an outcome known as the energy boomerang effect (York, 2012; York \& Bell, 2019). York (2012) conducted a cross-national study to assess whether increases in alternative energy production led to fossil fuel displacement. His analysis showed minimal displacement, a one quarter of a unit displacement of fossil fuel-based electricity by one unit produced via renewables. In addition, York (2016) found that increases in total energy and electricity production have occurred in conjunction with carbon intensity reductions from renewable energy. Expanding renewable energy thus does not necessarily displace fossil fuels and could lead to increases in development and energy consumption (York, 2012; York \& Bell, 2019). Thombs (2017) coined the term "renewable energy paradox" to describe the counterintuitive outcome that renewable 
energy has little effect in developed countries in reducing carbon emissions, which he attributes to outcomes associated with the treadmill of production (see Section 4.2). This production, which never ends, also involves increasing material throughput and concomitant energy demands. Renewable energy, according to Thombs, and supported by York and others, merely creates additional capacity for production rather than displacing fossil fuel-based energy consumption. In short, at this time, renewable energy development is merely energy addition rather than marking an energy transition (York \& Bell, 2019). The latter requires an explicit political program to simultaneously reduce fossil fuel development.

This evidence suggests that reliance on renewable energy is insufficient to meet carbon emission reduction targets. Trends and realities raise additional concerns. York (2016) has additionally shown that decarbonizing energy supplies and reducing carbon intensity, including increasing renewable energy capacity, has led to increases in both energy use and electricity production. World energy use is expected to increase by $28 \%$ and natural gas consumption by $43 \%$ by 2040 (IEA, 2017). Renewables are currently dominated by hydropower, and although wind and solar are projected to increase proportionally over this timespan they will still only account for roughly $10 \%$ of total energy production. The increase in overall energy consumption will rely heavily on fossil fuels. Even without the boomerang effect, emission reductions from renewables would be minimal. With the boomerang effect they will remain marginal. Failing to recognize these relationships represents a denial of (1) the inherent limitations of renewables, (2) the fettering of renewable energy development under current social conditions, (3) the inability of renewable energy development to displace fossil fuel development via market forces (i.e., fossil fuel development must be directly and rapidly reduced through political programs), and (4) the necessity for social changes that reduce overall energy use due to (1).

\subsection{Individualism}

Responses to environmental problems and climate change, particularly in the United States, often focus on individual actions. Norgaard (2011, p. 192) attributes this to the fact that "Americans are so immersed in the ideology of individualism that they lack the imagination or knowledge of alternative political means of response." Public campaigns around "reduce, reuse, recycle" have contributed to the notion that individuals are responsible for addressing climate change. Vandenbergh et al. (2007) suggest focusing on "low hanging fruit" to address climate change and promote buying the right lightbulbs among six other individual actions. The recommendations put forth by $\mathrm{Al}$ Gore in his documentary An Inconvenient Truth also focus on individual actions. Individual actions to address climate change have centered on driving hybrid or electric vehicles, not having children, and not flying, among others. 
Brulle and Dunlap (2015) note that most social science research on climate change comes from the economics literature, which focuses on individuals as rational actors. They cite Szerszynski and Urry (2010, p. 3) who state that this "has led to a focus on human practices as individualistic, market-based, and calculative, and has thus helped to strengthen a tendency towards a certain set of responses to climate change, ones based on individual calculation, technology and the development of new markets." Shove (2010) states that, "framing the problem of climate change as a problem of human behaviour marginalises and in many ways excludes serious engagement with other possible analyses, including those grounded in social theories of practice and transition" (p. 1274).

Focusing on individual actions creates societal ideas about how climate change has occurred (due to individual actions) and shapes ideas about how society should respond to it (through changes in individual actions).

Fixating on individual action diverts attention away from the structural changes needed to significantly reduce greenhouse gas emissions. Studies have indicated that implementing household actions to reduce emissions makes people less likely to support systemic changes that might have greater effects (carbon taxes, for example) (Werfel, 2017). Even if individuals do take action to reduce their carbon footprint, the financial savings they gain often go back into activities that act to shift the impacts elsewhere (Wapner \& Willoughby, 2005).

Most analyses that focus on individual or household actions pinpoint and quantify direct rather than indirect emissions, ignoring the most significant contributions to greenhouse gas emissions. According to Captick et al. (2014), direct emissions come from personal or home use while indirect emissions include those emissions "arising from consumption activities, through carbon embedded in products and services, such as food, consumer electronics, clothing and recreation" (p. 431). The authors note that estimates vary but that indirect emissions greatly exceed direct emissions. For example, according to the US Department of Energy, residential use represents only $34 \%$ of total energy use in the US, with commercial and industrial sectors using the majority (EIA, 2018). Failing to acknowledge indirect emissions not only focuses attention on relatively minor contributions but also creates the illusion that sufficient action has been taken.

Lastly, focusing on individual actions can mask the structural drivers of emissions. Brulle and Dunlap (2015, p. 8) state, "the core critique is that the individual-level focus of these disciplinary approaches tends to neglect institutional, social and cultural perspectives." Although the majority of emissions come from companies and states, not individuals (Heede, 2014), significant attention continues to focus on individual actions. Global shifts in policy, away from regulation and toward free market governance, have entrenched this thinking with significant consequences: 
A political-economic settlement designed to increase capital accumulation through deregulated markets and accelerating consumption results in reliance on tools for individual behaviour change. This is at best extremely limited as a means of engendering sustainable consumption, and at worst self-defeating. Questions of power and collective responsibility are marginalized, and the contradictions between neo-liberal capitalism and sustainable consumption are obscured. (Webb, 2012, p. 110)

Wapner and Willoughby (2005, p. 79) put it succinctly: "for most people most of the time, lifestyle changes are ecologically irrelevant." And yet, they remain a prominent focus in climate change discussions and contribute to a denial of the sociostructural changes necessary to reduce greenhouse gas emissions. A society that rapidly reduces emissions would certainly require significant lifestyle changes, but social structures would need to be reformulated to allow for and encourage the wide spread of necessary changes.

\subsection{Market fundamentalism}

Climate change has been referred to as a market failure, most famously by Nicholas Stern (2008) who called it the "biggest market failure the world has seen" (p. 1). A market failure arises when "firms have not met the full cost of their production and have imposed significant costs arising from pollution on society generally" (Andrew, 2008, p. 394). The Kyoto Protocol initiated a global market-based approach to reduce emissions, as did the emissions trading system in the European Union. Both failed early on to reduce emissions (Andrew, 2008).

Markets represent a space in which commodities can be bought and sold. Polanyi (2001) differentiated between commodities created explicitly for exchange and fictitious commodities. Carbon, and more specifically carbon emissions, represent a fictitious commodity. Kaup (2015, p. 291) argues that carbon markets are constructed by first setting a limit of emissions that will not negatively affect global climate, second turning carbon into a measurable credit, and third creating a market where carbon credits can be bought and sold. Carbon markets intend to reduce emissions but do not compel such an outcome. As the Kyoto meetings and resulting trading schemes highlight, carbon trading prioritizes economic outcomes first and foremost (Lohmann, 2010).

Lohmann (2010) identifies two kinds of primary carbon market-cap-and-trade, and carbon offsets - and shows how they operate. He suggests that "carbon markets isolate and objectify a new product that is difficult to define" (p. 237), and in so doing separate emissions from their political roots, leading to apolitical actions. Carbon markets create a market-based approach to a problem that dissolves the need for political and social action. Despite the shortcomings of carbon markets, many proponents of taking action on climate change support them. This includes perhaps the two most widely known climate activists, Al Gore and Bill McKibben, 
both of whom strongly support markets-illustrating the dominance of market fundamentalism. Foster (2010, pp. 4-5) uses the following quote from McKibben on this point: "There is only one lever even possibly big enough to make our system move as fast as it needs to, and that's the force of markets." This perspective denies the root causes of climate change, supports the same mechanisms driving greenhouse gas emissions, and masks the need to make social-structural changes.

\subsection{Green growthism}

In recent decades many approaches to addressing environmental sustainability have centered on green growth. Aimed at meeting both economic and environmental goals simultaneously, green growth has emerged as a central framing in climate and broader environmental discourses (Hickel \& Kallis, 2019). More specifically, green growth is often described as a win-win proposition-continuing economic growth while simultaneously meeting environmental outcomes and goals. In contrast to market fundamentalism (which represents a belief in the best mechanism to use), green growth (which could include market mechanisms) is a system in which proponents believe it is possible to address environmental harms while still growing the economy. Hallegatte et al. (2011, p. 3) explain succinctly: "green growth is about making growth processes resource-efficient, cleaner, and more resilient without necessarily slowing them," a seductive proposition but one that has many limitations and shortcomings.

The promise of green growth relies on decoupling environmental harm from economic activity and growth. Theoretically possible, such decoupling has not yet materialized (Hickel \& Kallis, 2019). Hickel and Kallis (2019) distinguish between relative and absolute decoupling. The former traces environmental impacts per unit of economic activity while the latter emphasizes overall reductions. Evidence exists to show relative decoupling, but not absolute (Schor \& Jorgenson, 2019). Absolute decoupling has not occurred for many reasons. Green growth lends itself to GDP (gross domestic product) measures, a metric that inadequately addresses environmental outcomes and well-being. Green growth also relies heavily on technological advances but these often center on efficiency improvements, which the above discussion shows to be inadequate in terms of reducing material throughput. Proponents argue that decoupling will emerge as economies transition away from material-based economies to ones based on services, but dematerialization has not occurred (Hickel \& Kallis, 2019). Lastly, evidence that developed nations have shown movement toward decoupling often fails to include the offshoring of emissions, those generated through shifting production to other countries (Hickel \& Kallis, 2019).

Green growth represents a denial of the fundamental relationship between economic growth and greenhouse gas emissions, which is an empirically illustrated positive correlation (Schor \& Jorgenson, 2019; Stern, 2006; York et al., 2003). 
Economic growth, in terms of GDP, directly relates to increased material production and includes carbon. For example, GDP growth of $1 \%$ equals a $0.6 \%$ growth in material use (Wiedmann et al., 2015) and a $0.5-0.7 \%$ increase in carbon emissions (Burke et al., 2015). Green growth denies this relationship and therefore fails to see a central root cause of climate change: a society structured around ever-increasing production and economic growth.

\section{Discussion}

Capital opposes reality and truth.

Enzo Paci (1972, p. 427)

\subsection{Returning to the concept of ideological denialism}

The forms of denialism outlined above all act to counter effective actions to reduce global carbon emissions. Although inaction on climate change is typically associated with the literal form of denialism and campaigns by fossil fuel companies and conservative actors to convince the public that climate change is not occurring, our conceptualization shows that denialism occurs from a broader range of actors. In particular, denial of important relationships and realities occurs even with individuals and groups who acknowledge anthropocentric climate change and who want immediate and effective actions to reduce emissions. These approaches, however, continue to implicitly or explicitly deny the root causes of climate change, thereby counteracting effective action. They contribute to ideological denialismthat is, ideas and practices underlying responses to climate change that:

1. Acknowledge that climate change is real and primarily driven by human activities, and that we should take immediate action to mitigate its current and projected serious harms.

2. Implicitly or explicitly misdiagnose the underlying social drivers of climate change, a misdiagnosis that is often embedded in proposed or real ineffective actions and laws.

3. Limit the suite of effective actions that could be adopted to challenge the social drivers of climate change. These limits are erected by either: (a) assuming that an ineffective strategy (e.g., lifestyle changes) are "realistic" and effective themselves, or (b) adopting ineffective strategies (e.g., carbon markets) in order to suppress strategies that would challenge the social drivers of climate change.

4. Maintain, rather than challenge, the current social order that drives climate change. 
This conceptualization builds upon and extends the three forms of denialism put forward by Cohen (2001). Rather than implicatory denial, in which climate change does not lead to moral implications and respective action (as Norgaard (2011) extends and applies in the context of climate change), ideological denial represents a failure to identify the proximate, causal drivers of the problem due to ideological beliefs proffered through culture, media, social norms, experience, and values.

Each form of denial outlined above has one fundamental characteristic in common: they all directly or indirectly focus on, maintain, or support continued economic growth necessitated by an adherence to the principle of capital accumulation. The relationship between economic growth and greenhouse gas emissions is the underlying contradiction that is concealed in some way by all of the solutions analyzed above. The discourse surrounding these forms of denial supports continued growth. For example, some neo-skeptics, as indicated by the quote from Curry (2014) above, focus on affordability: this translates into taking actions to address climate change in ways that do not infringe on economic growth. Geoengineering enables our economic system to continue unfettered, a primary rationale put forward by proponents (see Gunderson et al., 2019). Focusing on energy efficiency relies on technological improvements to existing energy production sources but does not in any way challenge the structure of energy systems whose operations are predicated on economic growth. Individual lifestyle changes not only do not challenge growth but can even promote growth: reliance on individual actions by consumers to address climate change is sometimes predicated on individuals buying more consumer products as the solution. This emphasis maintains and expands the hegemonic stature of economic growth in our society. Carbon markets and green growth have obvious associations with economic growth. Promoting renewable energy production as a solution to climate change, without simultaneously implementing programs to phase out fossil fuels, translates into more energy consumption and growth. Lastly, outright "literal" denial has been shown to be a result of deliberate efforts to protect the economic growth imperative. Collectively, all these forms of denial support economic growth propelled by capital accumulation at the cost of failing to reduce greenhouse gas emissions.

\subsection{Addressing the root drivers of climate change}

Techno-optimism, individualism, market fundamentalism, and green growthism in aggregate represent the ideological denial of climate change, a refusal to diagnose the root causes of climate change and what makes currently proposed solutions ineffective: the ever-increasing economic growth required by a growth-dependent capitalist system. This is well articulated by the treadmill of production (ToP) model, as introduced by Schnaiberg (1980) and elaborated by Gould et al. (2004). The ToP posits that as Western economies accumulate capital, technology replaces labor to increase overall profits. This leads to higher sunk costs and a necessity 
to increase productivity to continue and sustain further profit levels. This results in a treadmill of higher and higher levels of production. Increasing production depends on withdrawals from the environment (resource extraction) and additions to the environment (pollution), therefore increasing environmental impacts. ToP emphasizes production as the driver of impacts rather than consumption: consumers have relatively little power to influence firms. The goal of ever-increasing accumulation (in terms of profit and collective economic growth) drives production, consumption, and the associated harms to the environment (Gould et al., 2004). Our current capitalist system is driven by the ToP and will continue to result in increased material and energy throughput as well as greenhouse gas emissions, until we transform this system.

Therefore, an effective (or radical) solution to climate change has to start from the premise that this system, and economic growth in particular, is a significant driver of greenhouse gas emissions. A movement that has emerged in Europe and is spreading globally takes this reality as a starting point.

\subsubsection{Degrowth}

Degrowth presents an alternative to the sustainable development approach to addressing social and environmental concerns that supports economic growth. Rather than seeing economy and environment as equals, degrowth positions the economy within the environment. Degrowth focuses not solely on reducing material throughput but also squarely on prioritizing human and ecological wellbeing (Schneider et al., 2010). Meeting global emissions targets and preventing negative climate change consequences necessitates dematerialization, something that cannot happen under a growth paradigm (Hickel \& Kallis, 2019). Degrowth provides the framework for both reducing material throughput and focusing on well-being. It provides a path toward new social relations in a way that green growth, for example, cannot (Schneider et al., 2010).

Degrowth aims to create social relations that could overcome ideological denialism. In a society focused first and foremost on well-being, several proposed solutions to climate change criticized above would take on new meaning. To put this differently, calls for lifestyle changes, greener technology, and the expansion of renewables are not inherently a form of ideological denialism. Indeed, they are essential for achieving deep emissions reductions. These strategies are a form of ideological denialism when they do not simultaneously call for fundamental changes in existing structures of ownership and governance. For example, degrowth centers on ensuring that we do not have more but rather enough (Kallis \& March, 2015). In this context, alternative energy and energy efficiency policies and actions could be deployed in a way that would reduce overall energy use and demand (Gunderson, Stuart, Petersen, \& Yun, 2018). Furthermore, degrowth seeks to engage not just on how energy is produced but also who owns and has access to it (Kunze \& Becker, 
2015), further enabling renewables and efficiency measures to meet broad societal needs. Additional activities aimed at well-being have co-benefits related to energy use and carbon emissions. Complementary interventions-such as work-time reduction, low energy strategies in transportation (individual and system wide), low energy strategies aimed at individuals, new energy systems, bartering and alternative currencies, local agriculture, cooperatives, and co-housing, among others-in coordination provide opportunities to dematerialize society and drastically reduce emissions, while meeting human and non-human needs (Kallis et al., 2012). Collectively, these approaches present a viable pathway for meeting societal goals.

These initial steps and pathways hold great promise but require additional, systemic changes. Obviously, fossil fuel use has contributed greatly to greenhouse gas emissions. Not only do they have tremendous climate implications but they have social implications as well. Economic consolidation has led to 90 companies creating two thirds of all emissions since 1854 (Heede, 2014). This consolidation has led to powerful lobbies that have leveraged trillions in subsidies annually for the fossil fuel industry. Although fossil fuels have undoubtedly led to material well-being and myriad benefits to humanity, greenhouse gas emissions now pose a significant threat to humanity (Steffen et al., 2018). This reality has led some to call for buying out and nationalizing fossil fuel companies in order to then leave fossil fuels in the ground, negating further emissions and ameliorating the social and ecological consequences associated with fossil fuel extraction. Nationalizing or buying out these industries would open the door for a rapid reduction in carbon emissions and could also avert an economic disaster. In short, the future depends on our ability to keep fossil fuels in the ground and alter social relations in ways that reduce energy and material throughput in socially desirable ways.

\section{Conclusion}

Our goal here is not to cast blame or suggest that everyone who disagrees with this analysis must be an ideologue or a denialist. Rather, our analysis points out that ideological denialism functions long before it underpins coherent climate policies and academic discussion. To put this differently, our goal was not to dismiss ideas by labeling them with pejorative terms, but, instead, to bring to light ideas and practices that delay serious climate action despite good intentions.

The six forms of denialism we outline focus on climate change as a singular issue and put forth narrow solutions, failing to untangle the disparate social relations that have collectively caused the problem. Denialism, and ideological denialism in particular, obscure the root causes by focusing on climate change solutions that deny the need for sociostructural change and maintain the structural drivers of climate change situated in a growth-based paradigm. Ideology, manifested through 
ideas and practices, reproduces societal contradictions (Gunderson, 2017). These contradictions cannot be overcome through technology, markets, and individual actions. The hegemony of economic growth, compelled by the basic structure of the capitalist system, has created social norms and world views that conceal contradictions and limit viable solutions.

Degrowth, by contrast, seeks to uncover the proximate causes of climate change and the associated societal pathologies that created it (uneven power relations and associated societal outcomes: marginalization, vulnerability, and injustice). In particular, it diagnoses our social formation, which is structurally compelled to prioritize economic growth over other societal goals, as a central root cause. In doing so, degrowth begins identifying appropriate solutions, briefly described above, that could address this root cause.

We hope that the concept of ideological denialism will serve as a useful addition to Cohen's (2001) literal-interpretive-implicatory denial typology, as adopted and deepened by Norgaard (2011) in the context of climate change. Expanding from Foster (2010), ideological denialism refers to the ideas and practices underlying climate change responses that (1) acknowledge the reality, human origins, and severity of climate change and desire immediate action, (2) yet misdiagnose the structural drivers of climate change, (3) thereby limiting more effective actions, and (4) reproducing the social formation that drives climate change. The most harmful thread uniting the strategies that emanate from ideological denialism is an inability to envision alternative social futures, or an alternative to our current economic system. Marcuse (1964) termed this "one-dimensional" thinking, an outlook that is blind to possibilities latent in present social conditions, with a consequence perfectly captured in Murray Bookchin's (1990, n.p.) statement that the "assumption that what currently exists must necessarily exist is the acid that corrodes all visionary thinking." By undermining the ability to visualize social alternatives that address climate change, ideological denialism is both an outcome and reinforcer of onedimensionality. Importantly, this denial has kept environmentalists and others who actively want to reduce greenhouse gas emissions from promoting solutions to the systemic problems causing climate change. This includes policy-makers, academics, and everyday citizens who cannot see any alternatives outside our growth-dependent capitalist order. As a result, significant effort is necessary to overcome the ideological denialism that is currently widespread and deeply ingrained. Only by creating social awareness and solidarity around the need to organize society for well-being, instead of capital accumulation and continual economic growth, can we have any hope for drastically reducing climate change impacts in a socially just way. 


\section{References}

Althusser, L. (1971). Ideology and ideological state apparatuses. In L. Althusser (Ed.), Lenin and philosophy and other essays. Monthly Review Press.

Andrew, B. (2008). Market failure, government failure and externalities in climate change mitigation: The case for a carbon tax. Public Administration and Development, 28(5), 393-401.

Bookchin, M. (1990). The meaning of confederalism. Green Perspectives, (20). social-ecology. org/wp/1990/11/the-meaning-of-confederalism/

Boucher, O., Randall, D., Artaxo, P., Bretherton, C., Feingold, G., Forster, P., ... \& Zhang, X.Y. (2013). Clouds and aerosols. In Intergovernmental Panel on Climate Change, Climate change 2013: The physical science basis (pp. 571-658). Cambridge University Press. doi.org/10.1017/CBO9781107415324.016

Brulle, R. J., \& Dunlap, R. E. (2015). Sociology and global climate change. In R. E. Dunlap $\&$ R. Brulle (Eds.), Climate change and society: Sociological perspectives, (pp. 1-31). Oxford University Press. doi.org/10.1093/acprof:oso/9780199356102.003.0001

Burke, P. J., Shahiduzzaman, M., \& Stern, D. I. (2015). Carbon dioxide emissions in the short run: The rate and sources of economic growth matter. Global Environmental ChangeHuman and Policy Dimensions, 33, 109-121. doi.org/10.1016/j.gloenvcha.2015.04.012

Captick, S., Lorenzoni, I., Corner, A., \& Whitmarsh, L. (2014). Prospects for radical emissions reduction through behavior and lifestyle change. Carbon Management, 5(4), 429-445. doi.org/10.1080/17583004.2015.1020011

Cohen, S. (2001). States of denial: Knowing about atrocities and suffering. Polity.

Curry, J. (2014, October 9). The global warming statistical meltdown. The Wall Street Journal. wsj.com/articles/judith-curry-the-global-warming-statistical-meltdown-1412901060

Diethelm, P., \& McKee, M. (2009). Denialism: What is it and how should scientists respond. European Journal of Public Health, 19(1), 2-4. doi.org/10.1093/eurpub/ckn139

Dryzek, J. S., Goodin, R. E., Tucker, A., \& Reber, B. (2009). Promethean elites encounter precautionary publics: The case of GM foods. Science, Technology, \& Human Values, 34(3), 263-288. doi.org/10.1177\%2F0162243907310297

EIA (US Energy Information Administration). (2018). Electrical power annual [Data set]. Retrieved October 11, 2018, from eia.gov/electricity/annual/

Ferguson, F. (2018, August 24). John Bellamy Foster: Still time for an ecological revolution. Rebel News. rebelnews.ie/2018/08/24/john-bellamy-foster-there-is-still-time-for-anecological-revolution/

Foster, J. B. (2010, January 1). Why ecological revolution? Monthly Review, 61, 1-18. monthlyreview.org/2010/01/01/why-ecological-revolution/ 
Freire-Gonzalez, J. (2017). Evidence of direct and indirect rebound effect in households in EU-27 countries. Energy Policy, 102, 270-276. doi.org/10.1016/j.enpol.2016.12.002

Gould, K. A., Pellow, D. N., \& Schnaiberg, A. (2004). Interrogating the treadmill of production: Everything you wanted to know about the treadmill but were afraid to ask. Organization \&Environment, 17(3),296-316. doi.org/10.1177\%2F1086026604268747

Gramsci, A. (1971). Selections from the prison notebooks. International.

Gunderson, R. (2017). Ideology critique for the environmental social sciences: What reproduces the treadmill of production? Nature + Culture, 12(3), 263-289. doi.org/ $10.3167 /$ nc. 2017.120304

Gunderson, R., Petersen, B., \& Stuart, D. (2018). A critical examination of geoengineering: Economic and technological rationality in social context. Sustainability, 10(1), 1-21. doi.org/10.3390/su10010269

Gunderson, R., Stuart, D., Petersen, B., \& Yun, S. J. (2018). Social conditions to better realize the environmental gains of alternative energy: Degrowth and collective ownership. Futures, 99, 36-44. doi.org/10.1016/j.futures.2018.03.016

Gunderson, R., Stuart, D., \& Petersen, B. (2019). The political economy of geoengineering as plan B: Technological rationality, moral hazard, and new technology. New Political Economy, 24(5), 696-715. doi.org/10.1080/13563467.2018.1501356

Hallegatte, S., Heal, G., Fay, M., \& Treguer, D. (2011). From growth to green growth: A framework (Policy Research Working Paper 5872). The World Bank. doi.org/ $10.1596 / 1813-9450-5872$

Harvey, D. (1973). Social justice and the city. Johns Hopkins University Press.

Heede, R. (2014). Tracing anthropogenic carbon dioxide and methane emissions to fossil fuel and cement producers, 1854-2010. Climatic Change, 122(1-2), 229-241. doi.org/ $10.1007 / \mathrm{s} 10584-013-0986-\mathrm{y}$

Hickel, J., \& Kallis, G. (2019). Is green growth possible? New Political Economy, pp. 1-18. doi.org/10.1080/13563467.2019.1598964

IEA (International Energy Agency). (2017). Renewables 2017: Analysis and forecasts to 2022. webstore.iea.org/market-report-series-renewables-2017

IPCC (Intergovernmental Panel on Climate Change) (2018). Global warming of 1.5 degrees $C$. ipcc.ch/report/sr15/

Kallis, G., Kerschner, C., \& Martinez-Alier, J. (2012). The economics of degrowth. Ecological Economics, 84, 172-180. doi.org/10.1016/j.ecolecon.2012.08.017

Kallis, G., \& March, H. (2015). Imaginaries of hope: The utopianism of degrowth. Annals of the Association of American Geographers, 105(2), 360-368. doi.org/10.1080/0004560 8.2014.973803 
Kaup, B. (2015). Markets, nature, and society: Embedding economic and environmental sociology. Sociological Theory, 33(3), 280-296. doi.org/10.1177\%2F0735275115599186

Kavoulakos, K. (2017). Lukács' theory of reification and the tradition of critical theory. In M. J. Thompson (Ed.), The Palgrave handbook of critical theory (pp. 67-85). Palgrave. doi.org/10.1057/978-1-137-55801-5_4

Keith, D. W. (2013). A case for climate engineering. MIT Press.

Koonin, S. (2014, September 19). Climate science is not settled. The Wall Street Journal.

Kunze, C., \& Becker, S. (2015). Collective ownership in renewable energy and opportunities for sustainable degrowth. Sustainability Science, 10(3), 425-437. doi.org/10.1007/ s11625-015-0301-0

Lohmann, L. (2010). Uncertainty markets and carbon markets: Variations on a Polanyian theme. New Political Economy, 15(2), 225-254. doi.org/10.1080/13563460903290946

Lukács, G. (1971). History and class consciousness. MIT Press.

Marcuse, H. (1964). One-dimensional man. Beacon Press.

Marx, K., \& Engels, F. (1977). The German ideology. International Publishers.

McCright, A. M., \& Dunlap, R. E. (2000). Challenging global warming as a social problem: An analysis of the conservative movement's counter-claims. Social Problems, 47(4), 499522. doi.org/10.1525/sp.2000.47.4.03x0305s

McCright, A. M., \& Dunlap, R. E. (2003). Defeating Kyoto: The conservative movement's impact on US climate change policy. Social Problems, 50(3), 348-373. doi.org/10.1525/ sp.2003.50.3.348

McCright, A. M., \& Dunlap, R. E. (2010). Anti-reflexivity: The American conservative movement's success in undermining climate science and policy. Theory, Culture \& Society, 27(2-3), 100-133. doi.org/10.1177/0263276409356001

McCright, A. M., \& Dunlap, R. E. (2011). The politicization of climate change and polarization in the American public's views of global warming, 2001-2010. Sociological Quarterly, 52(2), 155-194. doi.org/10.1111/j.1533-8525.2011.01198.x

Mol, A. P. J. (2001). Globalization and environmental reform: The ecological modernization of the global economy. MIT Press.

Mooney, C. (2011, May/June). The science of why we don't believe science. Mother Jones. motherjones.com/politics/2011/04/denial-science-chris-mooney

Norgaard, K. M. (2011). Living in denial: Climate change, emotions and everyday life. MIT Press.

Oreskes, N., \& Conway, E. M. (2010). Merchants of doubt. Bloomsbury Press.

Paci, E. (1972). The function of the sciences and the meaning of man. Northwestern University Press. 
Perkins, J. H. (2015). Beware climate neo-scepticism. Nature, 522, 287-287. doi.org/ $10.1038 / 522287 \mathrm{c}$

Polanyi, K. (2001). The great transformation: The political and economic origins of our time. Beacon Press.

Raftery, A. E., Zimmer, A., Frierson, D. M. W., Startz, R., \& Liu, P. R. (2017). Less than 2 degrees $\mathrm{C}$ warming by 2100 unlikely. Nature Climate Change, 7, 637-641. doi.org/ $10.1038 /$ nclimate 3352

Ramos, V. (1982). The concepts of ideology, hegemony and organic intellectuals in Gramsci's Marxism. Theoretical Review, 30(3-8), 34.

Robock, A. (2008). Geoengineering: It's not a panacea. Geotimes, 53(7), 58-58.

Robock, A., Bunzl, M., Kravitz, B., \& Stenchikov, G. L. (2010). A test for geoengineering? Science, 327(5965), 530-531. doi.org/10.1126/science.1186237

Schleussner, C. F., Pfleiderer, P., \& Fischer, E. M. (2017). In the observational record half a degree matters. Nature Climate Change, 7, 460-462. doi.org/10.1038/nclimate3320 [See also author correction, Nature Climate Change 8, 257. doi.org/10.1038/s41558017-0055-z]

Schnaiberg, A. (1980). The environment. Oxford University Press

Schneider, F., Kallis, G., \& Martinez-Alier, J. (2010). Crisis or opportunity? Economic degrowth for social equity and ecological sustainability. Introduction to special issue. Journal of Cleaner Production, 18(6), 511-518. doi.org/10.1016/j.jclepro.2010.01.014

Schor, J. B., \& Jorgenson, A. K. (2019). Is it too late for growth? Review of Radical Political Economics, 51(2), 320-329. doi.org/10.1177\%2F0486613419831109

Shove, E. (2010). Beyond the ABC: Climate change policy and theories of social change. Environment and Planning A: Economy and Space, 42(6), 1273-1285. doi.org/10.1068 $\% 2 \mathrm{Fa} 42282$

Sorrell, S. (2009). Jevons' Paradox revisited: The evidence for backfire from improved energy efficiency. Energy Policy, 37, 1456-1469. doi.org/10.1016/j.enpol.2008.12.003

Steffen, W., Rockstrom, J., Richardson, K., Lenton, T. M., Folke, C., Liverman, D., ... \& Schellnhuber, H. J. (2018). Trajectories of the earth system in the Anthropocene. Proceedings of the National Academy of Sciences of the United States of America, 115(33), 8252-8259. doi.org/10.1073/pnas.1810141115

Stern, N. (2006). Stern review on the economics of climate change. Cambridge University Press. doi.org/10.1017/CBO9780511817434

Stern, N. (2008). The economics of climate change. American Economic Review, 98(2), 1-37. doi.org/10.1257/aer.98.2.1

Stern, P., Perkins, J. H., Sparks, R. E., \& Knox, R. A. (2016). The challenge of climatechange neoskepticism. Science, 353(6300), 653-654. doi.org/10.1126/science.aaf6675 
Supran, G., \& Oreskes, N. (2017). Assessing ExxonMobil's climate change communications (1977-2014). Environmental Research Letters, 12(8). doi.org/10.1088/1748-9326/aa815f

Szerszynski, B., \& Urry, J. (2010). Changing climates: Introduction [Special issue]. Theory, Culture \& Society, 27(2-3), 1-8. doi.org/10.1177/0263276409362091

Thombs, R. P. (2017). The paradoxical relationship between renewable energy and economic growth: A cross-national panel study, 1990-2013. Journal of World-Systems Research, 23(2), 540-564. doi.org/10.5195/jwsr.2017.711

United Nations Development Programme. (n.d.). Climate and disaster resilience. undp.org/ content/undp/en/home/climate-and-disaster-resilience/sustainable-energy/renewableenergy.html

Vandenbergh, M. P., Barkenbus, J., \& Gilligan, J. (2007). Individual carbon emissions: The low-hanging fruit. UCLA Law Review, 55(6), 1701-1758. uclalawreview.org/ individual-carbon-emissions-the-low-hanging-fruit/

Walsh, B. (2019, August 14). Why your brain can't process climate change. TIME [magazine]. time.com/5651393/why-your-brain-cant-process-climate-change/

Wapner, P., \& Willoughby, J. (2005). The irony of environmentalism: The ecological futility but political necessity of lifestyle change. Ethics \& International Affairs, 19(3), 77-89. doi.org/10.1111/j.1747-7093.2005.tb00555.x

Webb, J. (2012). Climate change and society: The chimera of behaviour change technologies. Sociology, 46(1), 109-125. doi.org/10.1177\%2F0038038511419196

Werfel, S. H. (2017). Household behaviour crowds out support for climate change policy when sufficient progress is perceived. Nature Climate Change, 7(7), 512-515. doi.org/ $10.1038 /$ nclimate3316

Wiedmann, T. O., Schandl, H., Lenzen, M., Moran, D., Suh, S., West, J., \& Kanemoto, K. (2015). The material footprint of nations. Proceedings of the National Academy of Sciences of the United States of America, 112(20), 6271-6276. doi.org/10.1073/pnas.1220362110

York, R. (2006). Ecological paradoxes: William Stanley Jevons and the paperless office. Human Ecology Review, 13(2), 143-147. humanecologyreview.org/pastissues/her132/ york.pdf

York, R. (2012). Do alternative energy sources displace fossil fuels? Nature Climate Change, 2, 441-443. doi.org/10.1038/nclimate1451

York, R. (2016). Decarbonizing the energy supply may increase energy demand. Sociology of Development, 2(3), 265-272. doi.org/10.1525/sod.2016.2.3.265

York, R., \& Bell, S. E. (2019). Energy transitions or additions? Why a transition from fossil fuels requires more than the growth of renewable energy. Energy Research Social Science, 51, 40-43. doi.org/10.1016/j.erss.2019.01.008 
York, R., \& Clark, B. (2010). Critical materialism: Science, technology, and environmental sustainability. Sociological Inquiry, 80(3), 475-499. doi.org/10.1111/j.1475-682X.2010. 00343.x

York, R., \& McGee, J. A. (2016). Understanding the Jevons paradox. Environmental Sociology, 2(1), 77-87. doi.org/10.1080/23251042.2015.1106060

York, R., Rosa, E. A., \& Dietz, T. (2003). Footprints on the earth: The environmental consequences of modernity. American Sociological Review, 68(1), 279-300. doi.org/ 10.2307/1519769 
This text is taken from Human Ecology Review, Volume 25, Number 2, 2019, published by ANU Press, The Australian National University, Canberra, Australia. doi.org/10.22459/HER.25.02.2019.08 